\title{
Cyclopentenylcytosine does not enhance cisplatin-induced radiosensitization in human lung tumour cells
}

\author{
HANS M. RODERMOND ${ }^{1}$, ROSEMARIE TEN CATE ${ }^{1}$, JAAP HAVEMAN ${ }^{1}$, ANDRÉ VAN KUILENBURG ${ }^{2}$, \\ JAN PAUL MEDEMA $^{1}$, CHRIS VAN BREE ${ }^{1}$ and NICOLAAS A.P. FRANKEN ${ }^{1}$ \\ ${ }^{1}$ Laboratory for Experimental Oncology and Radiobiology (LEXOR), Department of Radiation Oncology, \\ Center for Experimental Molecular Medicine, and ${ }^{2}$ Department of Clinical Chemistry, Emma Children's Hospital, \\ Academic Medical Center, University of Amsterdam, 1100 DE Amsterdam, The Netherlands
}

Received November 19, 2009; Accepted January 28, 2010

DOI: 10.3892/ol_00000095

\begin{abstract}
The search for agents that enhance the effect of ionizing radiation has been an object of study for decades. In this study, the sensitizing properties of cyclopentenylcytosine (CPEC) on radiation and cisplatin-induced radiosensitization in human squamous lung carcinoma cells were investigated. Human lung tumour SW-1573 cells (SWp, parental; SWg, gemcitabine-resistant) were incubated with CPEC and cisplatin and subsequently irradiated with different doses of $\gamma$-rays. Clonogenic survival was determined to measure the effectiveness of the treatments. CPEC (1 or $2 \mu \mathrm{M})$ treatment for $4 \mathrm{~h}$ decreased the plating efficiency to 75 and $50 \%$ in $\mathrm{SWp}$ and SWg cells, respectively. In the SWg cells, 0.1 and $1 \mu \mathrm{M}$ CPEC for $4 \mathrm{~h}$ enhanced the cell killing effect of cisplatin. However, an increase was not noted in the SWp cells. Due to the moderate toxicity of $1 \mu \mathrm{M}$ for $4 \mathrm{~h}$, this CPEC dose was used in the radiosensitization experiments. However, CPEC neither radiosensitized the lung tumour cells nor enhanced the radiosensitizing effect of cisplatin. A 2-h incubation with $4 \mu \mathrm{M}$ cisplatin also decreased the plating efficiency to $75-80 \%$ in the two cell lines. Using this cisplatin dose, radiosensitization was obtained in the two cell lines. Although cisplatin treatment clearly radiosensitized the lung tumour cells, CPEC treatment did not. Cisplatin-induced radiosensitization was also not enhanced by CPEC.
\end{abstract}

\section{Introduction}

Cisplatin is a drug widely used in the treatment of cancer and is often combined with radiotherapy. On the other hand, whether cyclopentenylcytosine (CPEC) has potential in anti-

Correspondence to: Dr Nicolaas A.P. Franken, Laboratory for Experimental Oncology and Radiobiology (LEXOR), Department of Radiation Oncology, Center for Experimental Molecular Medicine, P.O. Box 22700, 1100 DE Amsterdam, The Netherlands

E-mail: n.a.franken@amc.uva.nl

Key words: cyclopentenylcytosine, cisplatin, ionizing radiation, radiosensitization cancer treatment is currently under investigation (1-4). CPEC is cytotoxic to various cell types, and it sensitizes human colon carcinoma HT-29 cells to treatment with cisplatin (2). CPEC is a cytidine analogue, which, due to its intracellular activation to its 5'-triphosphate form, is a non-competitive inhibitor of cytidinetriphosphate synthetase. The exposure of cancer cells to CPEC results in the depletion of cellular CTP (cytidine 5'-triphosphate) and dCTP pools, leading to inhibition of RNA and DNA synthesis, as well as S-phase accumulation of mammalian cells $(3,5,6)$. Since CPEC induces depletion of CTP, one of the building blocks of DNA, it may influence the proper repair of DNA after exposure to ionizing radiation. Van Bree et al found that CPEC enhances the radiosensitization effect of gemcitabine in human pancreatic tumour cells; however, the radiosensitization effect of CPEC alone was only modest (3).

Cisplatin treatment induces DNA damage via the formation of interstrand and intrastrand crosslinks (7). Cisplatin crosslinks DNA in several different ways inducing cell cycle arrest, inhibition of DNA replication and transcription, and eventually apoptosis (8). The inhibition of DNA damage repair has also been implicated to be involved in the cytotoxicity of cisplatin (9). Therefore, cisplatin is an effective radiosensitizer used in combination with radiotherapy in a wide range of malignancies $(10,11)$. Cisplatin-induced radiosensitization occurs via the inhibition of the non-homologous end-joining pathway $(8,12)$.

Combination treatment of CPEC with cisplatin was investigated by Gharehbaghi et al $(1,2)$. A synergistic cytotoxicity was found in HT-29 cells after treatment of the cells, initially with $1 \mu \mathrm{M}$ CPEC and subsequently with cisplatin. Less synergy was found when cells were first incubated with cisplatin and then treated with CPEC.

Although favourable results have been obtained with the combination treatment of cisplatin and radiotherapy, relapses still occur. Therefore, trimodality treatments have been investigated in our laboratory. Bergs et al (11) observed that hyperthermia further increased the effects of combined cisplatin and radiation treatment in several human tumour cell lines. The present study investigated whether CPEC enhances cisplatin-induced radiosensitizing effects in human lung tumour cells. 


\section{Materials and methods}

Cell culture. The human NSCLC cell line SWp (parental SW-1573 cells, squamous cell carcinoma) and its gemcitabineresistant variant, $\mathrm{SWg}$, were grown at $37^{\circ} \mathrm{C}$ as monolayers in $75-\mathrm{cm}^{2}$ tissue culture flasks (Costar/Corning) in Leibovitz-15 medium (L-15; Gibco-BRL) supplemented with $10 \%$ fetal bovine serum, $2 \mathrm{mM}$ glutamine, $100 \mathrm{U} / \mathrm{ml}$ penicillin and 100 $\mathrm{mg} / \mathrm{ml}$ streptomycin. The $\mathrm{L}-15$ medium does not require $\mathrm{CO}_{2}$. The doubling time of the two cell types during exponential growth is $24 \mathrm{~h}$. In the $\mathrm{SWg}$ cell line, which is derived from SWp, the dCK gene is disrupted (13).

Irradiation. Irradiation was performed with $\gamma$-rays from a ${ }^{137} \mathrm{Cs}$ source. At a dose rate of $\sim 0.6 \mathrm{~Gy} / \mathrm{min}$, single doses up to 8 Gy were applied.

Clonogenic cell survival. Cells were plated at the appropriate cell numbers. After $2 \mathrm{~h}$, the cells were attached to the bottom of the plate and treated for $2 \mathrm{~h}$ with $0.1,1$ or $2 \mu \mathrm{M}$ CPEC (NSC 375575). The medium was then refreshed, and cells were treated for $2 \mathrm{~h}$ with $4 \mu \mathrm{M}\left(1.2 \mathrm{~g} / \mathrm{ml}\right.$ ) cisplatin (Platosin ${ }^{\circledR}$, Pharmachemie, Haarlem, The Netherlands). After this treatment, the medium was refreshed again, and the cells were irradiated. In control experiments, cells were treated with physiological salt solution, CPEC, cisplatin or radiation only. Subsequently, cells were incubated for 10 days. Surviving colonies were fixated and stained with glutaraldehyde-crystal violet solution and counted (14). Following dose D, surviving fractions $S(D) / S(0)$ were corrected for toxicity of CPEC or cisplatin alone, or a combination treatment of CPEC and cisplatin. Survival curves were analyzed using SPSS (Chicago, IL, USA) statistical software by means of fitting data by weighted linear regression, according to the linear-quadratic formula: $S(D) / S(0)=\exp -\left(\alpha D+\beta D^{2}\right)(15-19)$.

\section{Results}

To study the influence of CPEC on cisplatin radiosensitization, we initially determined the cytotoxicity of CPEC alone. Fig. 1 shows the toxicity of 1 and $2 \mu \mathrm{M}$ CPEC on SWp cells after different incubation times. A similar pattern was obtained for the SWg cells, indicating that an intact $\mathrm{dCK}$ activity is not required for CPEC cytotoxicity (data not shown). To investigate the cisplatin-sensitization by CPEC, cells were incubated for $2 \mathrm{~h}$ with 0.1 or $1 \mu \mathrm{M} \mathrm{CPEC}$. The concentrations were selected to compare almost no $(0.1 \mu \mathrm{M})$ and moderate $(1 \mu \mathrm{M})$ cytotoxicity of CPEC. In addition, the concentration of $1 \mu \mathrm{M}$ CPEC was described by Gharehbaghi et al to sensitize the cisplatin toxicity of HT-29 cells (2). As shown in Fig. 2A, the cytotoxicity of cisplatin in SWp cells was not increased by CPEC. However, in SWg cells the CPEC treatment enhanced the cell killing effect of cisplatin (Fig. 2B).

Fig. 3 shows the radiosensitization curves. The linearquadratic parameters of these radiation-dose survival curves are provided in Table I. Fig. 3 shows that cisplatin treatment clearly radiosensitized the lung tumour cells. This is evident from the value of the sensitizing enhancement ratios of the $\alpha$-parameter provided in Table I. The increase in the $\alpha$ value after cisplatin treatment was highly significant. However,

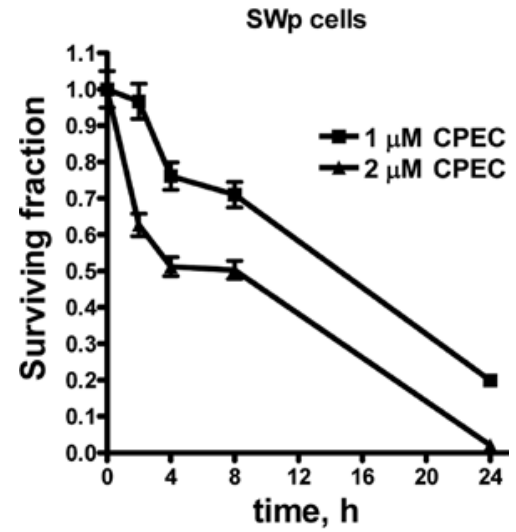

Figure 1. The toxicity of CPEC alone in SWp cells. Surviving fraction is plotted as a function of incubation time with 1 and $2 \mu \mathrm{M}$ of CPEC. Means with standard errors of at least three separate experiments are shown.

$\mathbf{A}$

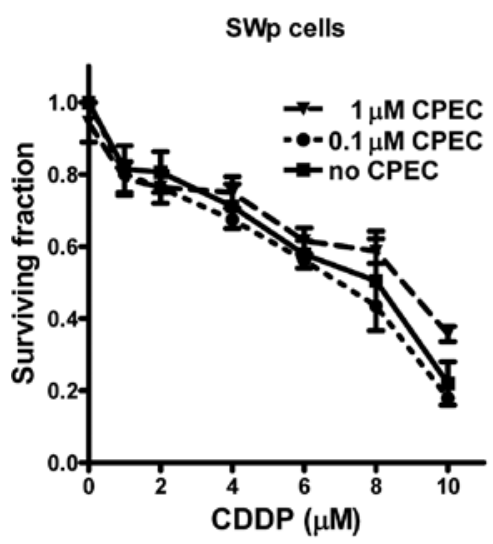

B

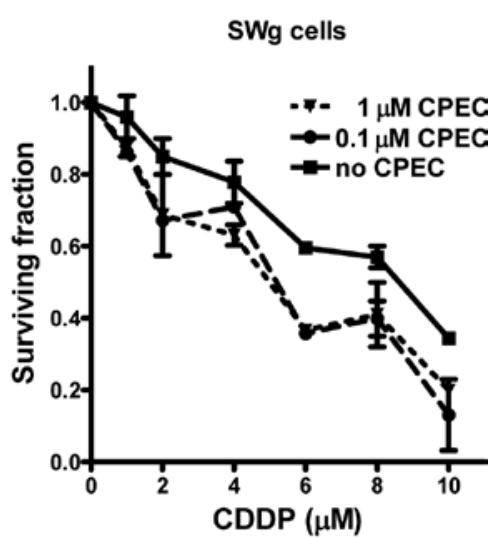

Figure 2. Sensitization of cisplatin ( $2 \mathrm{~h}$ ) by pre-incubation for $2 \mathrm{~h}$ with $0,0.1$ or $1 \mu \mathrm{M}$ CPEC in (A) SWp and (B) SWg cells. Means with standard errors of at least three experiments are shown.

CPEC treatment did not radiosensitize these cells, nor did it sensitize the cisplatin-induced radiosensitization. The slight increase noted in the $\alpha$ value of the SWp cells after CPEC and radiation was not significant.

\section{Discussion}

Our results show that $4 \mu \mathrm{M}$ of cisplatin with a 2-h incubation sensitized SW-1573 cells to ionizing radiation. In contrast to 
A

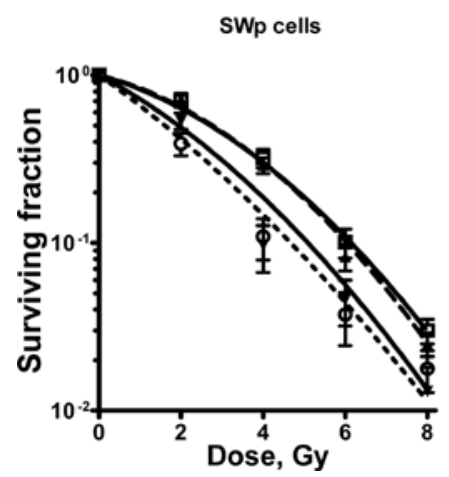

B

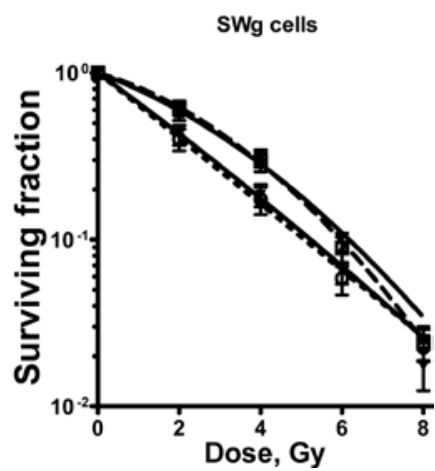

Figure 3. Survival curves of (A) SWp and (B) SWg cells after radiation only ( $\square$ ); radiation + preincubation with $1 \mu$ M CPEC ( $\mathbf{A})$; radiation + preincubation with $4 \mu \mathrm{M}$ cisplatin ( $\mathbf{v})$ and radiation $+1 \mu \mathrm{M} \mathrm{CPEC}+4 \mu \mathrm{M}$ cisplatin (O). Means with standard errors of at least three experiments are shown. Data of survival curves of combined treatments are corrected for the toxicity of CPEC only, cisplatin only and CPEC + cisplatin.

Table I. Linear-quadratic parameters and sensitizing enhancement ratios of linear-quadratic parameter $\alpha$.

\begin{tabular}{lccc}
\hline LQ parameter & $\alpha, \mathrm{Gy}^{-1}$ & $\beta, \mathrm{Gy}^{-2}$ & Sensitizer-enhancement ratio $\alpha^{\mathrm{a}}$ \\
\hline SWp cells & & & \\
$\quad$ Radiation only & $0.16 \pm 0.011$ & $0.038 \pm 0.003$ & 1.00 \\
Radiation $+1 \mu \mathrm{M}$ CPEC & $0.21 \pm 0.033$ & $0.027 \pm 0.009$ & $1.28 \pm 0.22$ \\
Radiation $+4 \mu \mathrm{M}$ cisplatin & $0.41 \pm 0.014$ & $0.006 \pm 0.004$ & $2.52 \pm 0.19^{\mathrm{b}}$ \\
Radiation $+1 \mu \mathrm{M}$ CPEC $+4 \mu \mathrm{M}$ cisplatin & $0.45 \pm 0.017$ & $0.001 \pm 0.005$ & $2.77 \pm 0.21^{\mathrm{b}}$ \\
SWg cells & & & 1.00 \\
Radiation only & $0.16 \pm 0.013$ & $0.035 \pm 0.007$ & $1.00 \pm 0.20$ \\
Radiation $+1 \mu \mathrm{M}$ CPEC & $0.16 \pm 0.029$ & $0.039 \pm 0.008$ & $1.88 \pm 0.18^{\mathrm{b}}$ \\
Radiation $+4 \mu \mathrm{M}$ cisplatin & $0.30 \pm 0.016$ & $0.030 \pm 0.010$ & $2.55 \pm 0.20^{\mathrm{b}}$ \\
Radiation $+1 \mu \mathrm{M}$ CPEC $+4 \mu \mathrm{M}$ cisplatin & $0.40 \pm 0.031$ & $0.021 \pm 0.011$ & \\
\hline
\end{tabular}

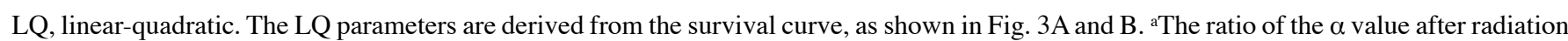
only and after a certain treatment. ${ }^{b}$ Significantly different from radiation only treatment and radiation $+\mathrm{CPEC}(\mathrm{p}<0.05)$.

Akudugu and Slabbert (20), who did not observe any radiosensitization of cisplatin in CHO cells after an $<8$-h incubation, we clearly showed that a 2 -h exposure to cisplatin radiosensitized SW-1573 cells. The difference may be due to the higher concentration of cisplatin used in our study ( 4 vs. $1.5 \mu \mathrm{M}$ used by Akudugu and Slabbert) or due to the different cell type. Bergs et al $(11,21)$ demonstrated that radiosensitization with cisplatin was concentration-dependent. Incubation with $5 \mu \mathrm{M}$ radiosensitized SW1573 cells, but that with $1 \mu \mathrm{M}$ cisplatin did not (11). Cisplatin radiosensitization has been shown for several different cell lines in a number of studies, and usually higher doses than $1 \mu \mathrm{M}$ were used (11,21-23). Wilkins et al (22) studied glioblastoma cells using higher concentrations $(12 \mu \mathrm{M})$ of cisplatin and a higher radiation dose (18 Gy). Begg et al (23) studied a RIF1 cell line and used similar concentrations of cisplatin and radiation dose as those in our study.

Our experimental design did not include the study of potentially lethal damage repair (PLDR), since the cells were not irradiated in the plateau phase, but were plated before irradiation. However, the cisplatin-induced radiosensitization in our study was likely due to an effect on PLDR, as shown by the increase in the linear parameter, $\alpha$. This is in agreement with the results found by Wilkins et al who observed inhibi- tion of potentially lethal damage recovery by cisplatin (22). Bergs et al also demonstrated that cisplatin-induced radiosensitization was due to the inhibition of PLDR $(11,21)$.

In the present study, CPEC sensitized cisplatin in the SWg cell line, but did not increase the cisplatin cytoxicity in the SWp cell line. The cell lines differ only in the fact that the SWg line is deoxycytidine kinase (dCK)-deficient (13), although this deficiency has no influence on the depletion of cellular CTP levels by CPEC (3). Therefore, it is difficult to explain why CPEC sensitized cisplatin in the one cell line but not in the other one. Gharehbaghi et al (2) clearly showed that pre-incubation with $1 \mu \mathrm{M}$ of CPEC sensitizes HT-29 cells to cisplatin.

In this study, incubation with CPEC neither sensitized these cells to ionizing radiation nor to cisplatin-induced radiosensitization. The radiosensitization properties of CPEC have been demonstrated in human pancreatic carcinoma cells upon incubation with gemcitabine $(3,4)$. In these studies, it was observed that CPEC, at low, clinically achievable and non-toxic doses, increased $\mathrm{dFdC}$ effectiveness; its radiosensitizing effect in human pancreatic carcinoma cells was also shown. However, CPEC alone did not radiosensitize these cells. This latter finding is in agreement with our findings in lung tumour cells. 
In conclusion, cisplatin sensitized the human lung tumour cells to ionizing radiation, but pre-treatment with CPEC neither enhanced cisplatin cytotoxicity nor the cisplatininduced radiosensitizing effects.

\section{Acknowledgements}

We would like to thank Mrs. Arabella Burgers and Mr. Daan van Abel for the technical assistance in the laboratory. The Maurits and Anna de Kock, and the Nijbakker Morra Foundations are acknowledged for sponsoring the laboratory equipment.

\section{References}

1. Gharehbaghi K, Zhen W, Fritzer-Szekeres M, Szekeres T and Jayaram HN: Studies on the antitumour activity and biochemical actions of cyclopentenyl cytosine against human colon carcinoma HT-29 in vitro and in vivo. Life Sci 64: 103-112, 1999.

2. Gharehbaghi K, Szekeres T, Yalowitz JA, Fritzer-Szekeres M, Pommier YG and Jayaram HN: Sensitizing human colon carcinoma HT-29 cells to cisplatin by cyclopentenylcytosine, in vitro and in vivo. Life Sci 68: 1-11, 2000.

3. Van Bree C, Rodermond HM, Leen R, Medema J and van Kuilenburg AB: Cyclopentenylcytosine increases gemcitabine radiosensitisation in human pancreatic cancer cells. Br J Cancer 98: 1226-1233, 2008.

4. Van Bree C, Barten-van Rijbroek AD, Leen R, Rodermond HM, van Kuilenburg $\mathrm{AB}$ and Kal HB: Cyclopentenyl cytosine has biological and anti-tumour activity, but does not enhance the efficacy of gemcitabine and radiation in two animal tumour models. Int J Oncol 34: 813-819, 2009.

5. Kang GJ, Cooney DA, Moyer JD, Kelley JA, Kim HY, Marquez VE and Johns DG: Cyclopentenylcytosine triphosphate. Formation and inhibition of CTP synthetase. J Biol Chem 264 713-718, 1989.

6. Bierau J, van Gennip AH, Leen R, Meinsma R, Caron HN and van Kuilenburg AB: Cyclopentenyl cytosine-induced activation of deoxycytidine kinase increases gemcitabine anabolism and cytotoxicity in neuroblastoma. Cancer Chemother Pharmacol 57: 105-113, 2006

7. Crul M, van Waardenburg RC, Beijnen JH and Schellens JH: DNA-based drug interactions of cisplatin. Cancer Treat Rev 28 291-303, 2002.

8. Myint WK, Ng C and Raaphorst GP: Examining the nonhomologous repair process following cisplatin and radiation treatments. Int J Radiat Biol 78: 417-424, 2002.

9. Lawrence TS, Blackstock AW and McGinn C: The mechanism of action of radiosensitization of conventional chemotherapeutic agents. Sem Radiat Oncol 13: 13-21, 2003.
10. Rose PG, Bundy BN, Watkins EB, Thigpen JT, Deppe G, Maiman MA, Clarke-Pearson DL and Insalaco S: Concurrent cisplatin-based radiotherapy and chemotherapy for locally advanced cervical cancer. N Engl J Med 340: 1144-1153, 1999.

11. Bergs JW, Haveman J, ten Cate R, Medema JP, Franken NA and van Bree C: Effect of $41^{\circ} \mathrm{C}$ and $43^{\circ} \mathrm{C}$ on cisplatin radiosensitization in two human carcinoma cell lines with different sensitivities for cisplatin. Oncol Rep 18: 219-226, 2007.

12. Haveman J, Castro Kreder N, Rodermond HM, van Bree C, Franken NA, Stalpers LJ, Zdzienicka MZ and Peters GJ: Cellular response of X-ray sensitive hamster mutant cell lines to gemcitabine, cisplatin and 5-fluorouracil. Oncol Rep 12: 187-192, 2004.

13. Van Bree C, Castro Kreder N, Loves WJ, Franken NA, Peters GJ and Haveman J: Sensitivity to ionizing radiation and chemotherapeutic agents in gemcitabine-resistant human tumour cell lines. Int J Radiat Oncol Biol Phys 54: 237-244, 2002.

14. Franken NA, Rodermond HM, Stap J, Haveman J and van Bree C: Clonogenic assay of cells in vitro. Nat Protoc 1: 2315-2319, 2006.

15. Barendsen GW, van Bree C and Franken NA: Importance of cell proliferative state and potentially lethal damage repair on radiation effectiveness: Implications for combined tumour treatments (Review). Int J Oncol 19: 247-256, 2001.

16. Barendsen GW: Parameters of linear-quadratic radiation doseeffect relationships: dependence on LET and mechanisms of reproductive cell death. Int J Radiat Biol 71: 649-655, 1997.

17. Franken NA, van Bree C, Veltmaat MA, Rodermond HM, Haveman J and Barendsen GW: Radiosensitization by bromodeoxyuridine and hyperthermia: analysis of linear and quadratic parameters of radiation survival curves of two human tumour cell lines. J Radiat Res 42: 179-190, 2001.

18. Franken NA, van Bree C, Kipp JBA and Barendsen GW: Modification of potentially lethal damage in irradiated Chinese hamster V79 cells after incorporation of halogenated pyrimidines. Int J Radiat Biol 72: 101-109, 1997.

19. Franken NA, van Bree C, Streefkerk JO, Kuper IMJA, Rodermond HM, Kipp JBA, Haveman J and Barendsen GW: Radiosensitization by iodo-deoxyuridine in cultured SW-1573 human lung tumour cells: Effects on $\alpha$ and $\beta$ of the linearquadratic model. Oncol Rep 4: 1073-1076, 1997.

20. Akudugu JM and Slabbert JP: Modulation of radiosensitivity in Chinese hamster lung fibroblasts by cisplatin. Can J Physiol Pharmacol 86: 257-263, 2008.

21. Bergs JW, Franken NA, ten Cate R, van Bree C and Haveman J: Effects of cisplatin and gamma-irradiation on cell survival, the induction of chromosomal aberrations and apoptosis in SW-1573 cells. Mutat Res 594: 148-154, 2006.

22. Wilkins DE, Heller DP and Raaphorst GP: Inhibition of potentially lethal damage recovery by cisplatin in a brain tumour cell line. Anticancer Res 13: 2137-2142, 1993.

23. Begg AC, van Der Kolk PJ, Dewit L and Bartelink H: Radiosensitization by cisplatin of RIF1 tumour cells in vitro. Int J Radiat Biol 50: 871-884, 1986. 